\title{
O IMPACTO DO TRATAMENTO DA DISFUNÇÃO ERÉTIL SOBRE O CASAL
}

Zenilce Vieira Bruno ${ }^{1}$; Paulo Henrique de Moura Reis ${ }^{2}$

\section{IMPACT OF ERECTILE DYSFUNCTION TREATMENT IN THE COUPLE}

Resumo: A disfunção erétil é quase sempre de ordem psicológica, causas mais profundas e mais remotas, como conflito inconsciente ou desarmonia conjugal, podem ser à base das tensōes que causam o problema sexual e continuam a evocar a ansiedade quando se tenta transar. O distúrbio sexual, embora seja de um dos parceiros, compromete a ambos. Um elemento crucial a ser visto nos casos de disfunção sexual é a relação diádica. Há situações conjugais já tão comprometidas que impossibilitam a terapia sexual, devendo o casal ser primeiramente submetido a uma terapia de casal, que é proposta para aqueles com maior comprometimento do relacionamento afetivo. $\mathrm{O}$ ato sexual que deveria ser uma atividade descontraída e prazerosa convertese em um jogo de expectativas. Não são duas pessoas que se encontram no amor e sim duas ansiedades que se reúnem, se observam, se avaliam, gerando um processo inibidor de alta potência destruidora.

Palavras-chave: Disfunção sexual; casal; tratamento.

Abstract: The erectile dysfunction is almost always of psychological order. Deep and remote causes like unconscious conflicts or couple disharmonies can be the base for the tensions that cause the sexual problem and keep evocating anxiety when the couple tries to have sex. The sexual disturb, even tough is inside one of the partners, it stops belonging to just one, but both. The crucial element that should be seen is the everyday relationship. Some conjugal relationships are already so deteriorated that makes the sexual therapy impossible, needing that the couple goes for a marital therapy first;

Psicóloga Clínica, Psicodramatista e Terapeuta Sexual. e-mail: zenilcebruno@uol.com.br

2 Urologista do Hospital Universitário da Universidade Federal do Ceará. e-mail: phmreis@secrel.com.br 
that is the proposal for the couples that have an affective relationship more worn down. The sexual act, that should be an informal activity and more pleasurable, turns into a game of expectations, there are not two people that found in love anymore, but two anxious people that get together to watch and evaluate each other, originating a inhibiter process that is of high destructive potency.

Keywords: Dysfunction sexual; couple; treatment

A nossa experiência clínica no processo terapêutico, iniciado pelas dificuldades relativas ao tratamento de problemas sexuais, permite-nos relatar que, dentre as disfunções sexuais, a disfunção erétil é a que provoca maior número de complicações para o homem na sua sexualidade. As limitações conseqüentes acabam causando perturbações em todas as áreas de sua vida. $\mathrm{O}$ homem ao se reprimir, limitando sua sexualidade, distorce a realidade, deixando-se levar então por atitudes, fantasias e sentimentos negativos, podendo leválo ao desequilíbrio interior, afetando sua saúde mental, física e emocional.

Para o homem, a dificuldade erétil é quase sempre de ordem psicológica, entretanto causas mais profundas e mais remotas, como conflito inconsciente ou desarmonia conjugal, podem freqüentemente ser à base das transações tensas que causaram o problema sexual específico e continuar a evocar a ansiedade quando tentarem fazer amor. $\mathrm{O}$ distúrbio sexual embora esteja alojado em um dos membros do casal, no homem, neste caso, não é apenas desse membro. O problema sexual torna-se de ambos.

Muitas vezes, é difícil para o paciente assumir junto a sua parceira sexual sua impotência, o que para este, associa-se à falta de masculinidade e à perda de sua própria identidade, reforçando seus mecanismos inconscientes de defesa de ego, visivelmente neste caso, inadequados e imaturos, impedindoo de solucionar problemas. Em abordagem multidisciplinar, o paciente tende a aceitar mais facilmente, a necessidade em trazer à terapia a parceira sexual, pois já vem com a informação, quando encaminhado por um médico, de que será necessário que a parceira participe do tratamento.

Freqüientemente, o paciente começa a ver sua parceira conjugal como a maior responsável. Também fica preocupado que ela conheça completamente as dimensões de sua inadequação sexual e, com isso o grau de presumível perda de masculinidade. $\mathrm{O}$ fato de mais alguém conhecer sua inadequação sexual é realmente ameaçador para a afirmação sexual de muitos homens. Para 
alguns, esse conhecimento da parceira também constitui uma ameaça à confiança social. Os homens ficam preocupados que elas comentem sua inadequação sexual com outras pessoas e, infelizmente algumas fazem exatamente isso.

As mulheres traumatizam o companheiro sexualmente desajustado, da mesma forma que ele menospreza a companheira sexualmente desajustada, por uma variedade de razões que se somam à frustração ou à revanche. É claro que muitas delas não discutem publicamente a disfunção sexual do seu casamento. Podem até pensar que a disfunção dele tem origem, ou pelo menos é aumentada por falta de atrativos delas, ou que forçaram o desajuste pela ausência de competência sexual. Algumas mulheres usam o mecanismo da sublimação para superar esta situação conflituosa; outras se desgastam ainda mais com seus ressentimentos e rancores, o já precário equilíbrio conjugal piora, quando não se agridem. Tudo isso promove o aparecimento de sintomas que vão da insônia a irritabilidade e à amargura, das depressões leves aos quadros graves de enfermidade psicossomáticas de grande poder autodestrutivo.

Alguns pacientes levam anos para buscar ajuda e só o fazem quando temem que sua mulher procure outros homens para se realizar ou quando outra esteja se insinuando e que não querem desapontar. $\mathrm{O}$ conceito cultural de que o homem deve aceitar total responsabilidade no estabelecimento da união sexual bem sucedida, colocou sobre eles o peso psicológico do processo de coito e aliviou as mulheres de qualquer sugestão de responsabilidade similar no seu fracasso. As diferenças do sexo na reação psicológica à disfunção sexual são determinadas pela cultura. Espera-se que o homem funcione sexualmente e quando tal não acontece, esta disfunção é encarada como patológica.

Um elemento crucial a ser visto nos casos de disfunção sexual é a relação diádica. Quando o casal traz algum nível de desgaste no relacionamento, o mesmo deve ser trabalhado num primeiro momento, no entanto é importante perceber se este nível de dificuldade conjugal é muito extremo impedindo uma melhoria do relacionamento e do problema sexual. Há situações conjugais já tão comprometidas que impossibilitam a terapia sexual, devendo o casal ser primeiramente submetido a uma terapia de casal.

Às vezes, a origem da disfunção sexual está relacionada à relação dual e não ao conflito intrapsíquico do indivíduo. Cada membro do casal, neste caso, pode contribuir para melhorar ou piorar o desempenho sexual do outro. Auto-estima rebaixada pode induzir a escolhas mútuas, no intuito inconsciente de promover uma união simbiótica, objetivando equilibrar a auto-avaliação 
dos componentes do par. Percebendo que a premissa de complementação pelo outro não se dará, cada membro do casal se vê frustrado e competindo com o outro de forma latente ou manifesta, no intuito de apropriar-se imaginariamente das aptidōes do parceiro para tornar-se completo. Isso gera um clima em que não há lugar para o sexo, mas para a destrutividade. Por essa perspectiva, a disfunção erétil constitui um instrumento contra a parceira, utilizado inconscientemente quando o "impotente" garante à mulher que ela não lhe dá prazer, taxando-a de incapaz e inferiorizando-a. No caso da disfunção erétil, o casal que se forma une usualmente uma mulher castradora e um homem impotente.

É comum a parceira do paciente com disfunção apresentar dificuldades relacionadas à sua sexualidade. Caso seja uma parceira fixa, que está envolvida com o paciente durante vários anos com a presença da queixa, não é raro ela viver uma frustração e desmotivação para com o relacionamento em conseqüência de sua insatisfação sexual. Com o passar do tempo, muitas dessas parceiras perdem o total interesse na relação, não se empenhando mais em querer melhorar o relacionamento, o que dificulta a sua participação no tratamento. Por outro lado, à mulher pode apresentar comportamento que visa estimular o homem, mas que em vez de sexualmente excitante se torna inibidor. A não comunicação desse fato pode potencializar as dificuldades. Desse modo, o sexo perde seu caráter de espontaneidade, exatamente o que viabilizaria o prazer.

Alguns pacientes não acham necessária a participação das parceiras, alegando ser a queixa sexual um problema exclusivo deles. Com isto, não passam a elas a convocação feita pelo terapeuta. Em contra partida, algumas parceiras recebem a comunicação verbal, mas se recusam a ir, alegando não ter responsabilidade sobre a queixa do paciente.

A terapia sexual somente será indicada quando houver um clima de espontaneidade de respostas eróticas e de permissividade para toques de carícias que culminem na relação sexual. $O$ processo de terapia sexual pode ser o caminho para o desenvolvimento desta permissividade e clima de espontaneidade, além de facilitar enormemente a comunicação do casal.

Para a psicoterapia individual são indicados os pacientes que apresentam conflitos intrapsíquicos ligados à queixa sexual, ou que não tenham uma parceira fixa, ou ainda para aqueles que a parceira não apresenta disponibilidade para participar de outro tipo de terapia com o paciente. Deve-se levar em conta a aptidão desses pacientes para a introspecção e conhecimento de sua vida emocional. 
A terapia sexual é indicada para aqueles pacientes que apresentam uma organização psicológica rigidamente defensiva, com dificuldades, com resistências à psicoterapia, e que podem contar com a participação da parceira. A terapia conjugal é proposta para os casais com maior comprometimento do relacionamento afetivo. $\mathrm{O}$ ato sexual que deveria ser uma atividade descontraída e prazerosa converteu-se em um jogo de expectativas. Não são duas pessoas que se encontram no amor e sim, duas ansiedades que se reúnem, se observam, se avaliam, gerando um processo inibidor de alta potência destruidora.

Não são os "sintomas" das perturbações individuais o que tumultua a relação. É preciso cuidado, por isso mesmo, ao lidar com o que se defina individualmente como "sintoma" de cada um, e a ênfase maior deve-se orientar pela lógica de ação e reação do conjunto, ou seja, pelas regras de interação. $\mathrm{O}$ casal constitui um sistema dinâmico no qual um reage à ação do outro, interpretando a realidade ao seu próprio modo. Grandes crises podem advir quando o sistema defensivo de um é inadvertidamente acionado pelo outro. Somos movidos a sonhos e interpretações da realidade, não temos acesso às verdades dos outros, mas apenas ao que pensamos que são essas verdades.

É importante lembrar que o aparecimento e a manutenção psicogênica do bloqueio eretivo, depende muito de como o indivíduo vivencia suas experiências, e como estas experiências foram consolidadas por mecanismos reforçadores.

Os objetivos primários no tratamento da disfunção erétil são: remover os medos da performance sexual, reorientar seu padrão comportamental involuntário, para que ele se torne um participador ativo, afastado do papel de espectador habitual e minorar os medos da parceira com relação à performance sexual dele. Empregamos medidas para combater a ansiedade através de técnicas de relaxamento, dessensibilização dos fatores de ansiedade e até mesmo na fase aguda e por pouco tempo, o emprego criterioso de psicofármacos.

Entre os procedimentos mais significativos da terapia sexual está a focagem das sensações. Ele é de grande importância para melhorar o relacionamento diádico desgastado. $\mathrm{O}$ fato das pessoas se tocarem, se estimularem, se comunicarem de modo não-verbal, favorece extraordinariamente a comunicação do par, abrindo novos canais de entendimento.

É interessante assinalar as possíveis reaçōes que são observadas no tratamento das disfunções eréteis. À medida que os progressos se evidenciam, geralmente uma sensação de euforia e satisfação envolve os parceiros. Há casos, porém, em que a dificuldade erétil está associada a certos ganhos secundários. Evidentemente, nestes casos, a melhora determina certo grau de ansiedade. 
Um fenômeno esperado são os obstáculos, conscientes ou inconscientes, que são postos ao tratamento. Estas "resistências" ou "sabotagens" podem surgir de forma sutil e velada, como a perda de interesse pelo tratamento, crítica ao parceiro, exigência crescente ou se evidenciar de uma forma clara a queixa de que o tratamento é tedioso, mecânico e trabalhoso. Algumas mulheres assumem um relacionamento extraconjugal exatamente quando o marido começa a apresentar boas ereções. É claro que muitas dessas "resistências" estão alimentadas por sentimentos de insegurança, medo de perder o parceiro ou a posição autoritária na direção da família.

O tratamento realizado não pode ser muito lento, pois algumas vezes as inadequações sexuais corroem de tal forma o relacionamento, que muitos desistem da terapia e do casamento. É necessário agilizar o processo, através de uma terapia breve que seja suficientemente eficaz para restaurar os laços entre os pares, antes que eles se desfaçam por completo.

\section{Bibliografia consultada}

ABDO, C.N. Sexualidade humana e seus transtornos. 2a ed.. São Paulo: Lemos Editorial, 2000.

BRAGANTE, L. Amor e sexualidade: a resolução dos preconceitos. $2^{\mathrm{a}}$ ed., São Paulo: Gente, 1994.

CARIDADE, A. Sexualidade. Corpo e metáfora. São Paulo: Iglu, 1997.

CAVALCANTE, R.C. Tratamento psicológico da disfunção erétil: manual prático de orientação clínica. São Paulo: Ponto, 2005.

COSTA, M. Amor e sexualidade. São Paulo: Editora Gente, 1994.

DIAS, V.R.C.S. Vínculo conjugal na análise psicodramática: diagnóstico estrutural dos casamentos. São Paulo, Agora, 2000.

FOUCALT, M. Historia da sexualidade. 3 vols., Rio de Janeiro: Graal, 1998.

GILLAN, R. A Terapia Sexual. 7a ed. Lisboa, 1988.

GLINA, S. (Im) potência sexual. São Paulo: Contexto, 1997.

KAPLAN, H.S. A nova terapia do sexo: tratamento dinâmico das disfunçōes sexuais. Rio de Janeiro:Nova Fronteira, 1977.

MASTER, W. \& JONHSON, V. A Resposta Sexual Humana. São Paulo: Roca, 1984.

MURARO, R. M.; BOFF, L. Feminino e masculino. Uma nova consciência para os encontros das diferenças. Rio de Janeiro: Sextante, 2002.

REICH, W. A função do orgasmo. São Paulo: Brasiliense, 1983. 